\title{
Neural Control of Neutralization Process using Fuzzy Inference System based Lookup Table
}

\author{
Parikshit Kishor Singh \\ BITS Pilani, Pilani Campus \\ Dept. of EEE/INSTR \\ Rajasthan-333031, India
}

\author{
Surekha Bhanot \\ BITS Pilani, Pilani Campus \\ Dept. of EEE/INSTR \\ Rajasthan-333031, India
}

\author{
Harekrishna Mohanta \\ BITS Pilani, Pilani Campus \\ Dept. of Chemical Engg. \\ Rajasthan-333031, India
}

\begin{abstract}
Over a number of years, $\mathrm{pH}$ control of neutralization process is recognized as a benchmark for modeling and control of nonlinear processes. This paper first describes dynamic modeling of $\mathrm{pH}$ neutralization process. Thereafter fuzzy logic based $\mathrm{pH}$ control scheme for neutralization process is developed. Further, a two-dimensional (2-D) lookup table is generated based on defuzzification mechanism of fuzzy inference system (FIS). Finally, using this lookup table, a neural network control for $\mathrm{pH}$ neutralization process is developed. Performances of fuzzy logic based control and lookup table based neural network control for servo and regulatory operations are compared based on integral square error (ISE) and integral absolute error (IAE) criterions. Results indicate that lookup table based neural network control performs better than fuzzy logic based control.
\end{abstract}

\section{General Terms}

Nonlinear process control, fuzzy logic control, neural network control.

\section{Keywords}

Fuzzy logic, lookup table, neural network, neutralization process, $\mathrm{pH}$ control.

\section{INTRODUCTION}

Control of $\mathrm{pH}$ plays a pivotal role in many modern industrial applications such as boiler feedwater treatment in thermal power plant, wastewater treatment in paper and pulp industry, biopharmaceutical manufacturing, and chemical processing. However, due to high nonlinearity and time-varying parameters, control of $\mathrm{pH}$ is difficult and demanding. Further, modern process industries require more accurate, robust and flexible control systems for efficient and reliable operations. To meet these stringent demands, intelligent control strategies are increasingly being employed in modern process industries.

Development of the first-principle based dynamic modeling of $\mathrm{pH}$ neutralization process involves material balance on selective ions, equilibrium constants and electroneutrality equation [1]. The associated model has been used by researchers as a platform for many subsequent investigations and forms the basis to introduce new and improved forms of dynamic modeling and $\mathrm{pH}$ control of neutralization process using the concept of reaction invariant and strong acid equivalent [2], [3]. Many different and practical approaches for $\mathrm{pH}$ control based on feedforward and gain scheduling techniques have also been proposed in the literature [4], [5], [6], [7].

The term "fuzzy logic" gives an impression of vague logic. In reality, the term "fuzzy logic" refers to the fact that that the logic involved can deal with lexical definition of inputs, in contrast to binary logic which accepts only "true" or "false". Therefore, the term "fuzzy" in fuzzy logic applies to the imprecision in the data and not in the logic [8]. Fuzzy logic based intelligent control can be described as a control approach that is evolved based on experience and intuitive understanding of process and is used to synthesize linguistic control rules of a skilled operator. Since its origination, many people from both academic and industrial communities have devoted considerable effort for development of theoretical research and application techniques on fuzzy logic [9], [10], [11]. Literature review shows that application of fuzzy logic to conventional control techniques such as PID control, sliding mode control, and adaptive control, results in improved performance for the hybrid controller over their conventional counterparts [12], [13], [14].

A neural network can be considered as a computer program that emulates the human brain and is designed to learn by example and past experience. In past few decades, neural networks based intelligent control techniques have received great attention and undergone substantial development. Because of its ability to handle nonlinearities, neural network based model-free control techniques have provided promising solutions for many nonlinear problems, especially in the field of nonlinear chemical processes [15]. Finally, integration of expert knowledge from fuzzy logic and adaptive learning capabilities of neural network results in neuro-fuzzy control. It has been recognized that the neuro-fuzzy control techniques, such as adaptive network fuzzy inference system (ANFIS), provides better control strategy [16].

\section{DYNAMIC pH PROCESS MODEL}

The $\mathrm{pH}$ neutralization process takes place in continuous stirred tank reactor (CSTR) with perfect mixing and constant maximum volume. As shown in Fig. 1, the CSTR has two influent streams: the hydrochloric acid as titration stream (feed A) and the sodium hydroxide as process stream (feed B), and one outlet stream: the effluent stream. The peristaltic pumps $\mathrm{A}$ and $\mathrm{B}$ regulate the flow of feed $\mathrm{A}$ and feed $\mathrm{B}$ respectively. The flow characteristics of peristaltic pumps A and $\mathrm{B}$ are identical.

The dynamic model of $\mathrm{pH}$ neutralization process involves material balances on selective ions, equilibrium relationship, and electroneutrality equation. Based on principle of material balances the process mixing dynamics may be described as follows:

$$
\begin{aligned}
& \mathrm{V} \frac{\mathrm{dx}_{\mathrm{a}}}{\mathrm{dt}}=\mathrm{F}_{\mathrm{a}} \mathrm{C}_{\mathrm{a}}-\left(\mathrm{F}_{\mathrm{a}}+\mathrm{F}_{\mathrm{b}}\right) \mathrm{x}_{\mathrm{a}} \\
& \mathrm{V} \frac{\mathrm{dx}_{\mathrm{b}}}{\mathrm{dt}}=\mathrm{F}_{\mathrm{b}} \mathrm{C}_{\mathrm{b}}-\left(\mathrm{F}_{\mathrm{a}}+\mathrm{F}_{\mathrm{b}}\right) \mathrm{x}_{\mathrm{b}}
\end{aligned}
$$

where $\mathrm{V}$ is the maximum volume of the CSTR $(1.9 \mathrm{~L}) ; \mathrm{C}_{\mathrm{a}}, \mathrm{F}_{\mathrm{a}}$ are the concentration $(0.05 \mathrm{~mol} / \mathrm{L})$ and flow rate $(0$ to 6.23 
$\mathrm{mL} / \mathrm{s})$ of titration stream $\mathrm{A} ; \mathrm{C}_{\mathrm{b}}, \mathrm{F}_{\mathrm{b}}$ are the concentration (0.05 $\mathrm{mol} / \mathrm{L}$ ) and flow rate $(0$ to $6.23 \mathrm{~mL} / \mathrm{s}$ ) of process stream $\mathrm{B}$; $\mathrm{F}_{\mathrm{a}}+\mathrm{F}_{\mathrm{b}}$ is the flow rate of effluent stream; $\mathrm{x}_{\mathrm{a}}$ is the concentration of acid component (chloride ion, $\mathrm{Cl}^{-}$) in the effluent stream; $\mathrm{x}_{\mathrm{b}}$ is the concentration of base component (sodium ion, $\mathrm{Na}^{+}$) in the effluent stream.

The equilibrium relationship for water is given as

$$
\mathrm{K}_{\mathrm{w}}=\left[\mathrm{H}^{+}\right]\left[\mathrm{OH}^{-}\right]
$$

where $\mathrm{K}_{\mathrm{w}}$ is the dissociation constant of water $\left(10^{-14}\right)$.

From the electroneutrality condition, we have

$$
\left[\mathrm{Na}^{+}\right]+\left[\mathrm{H}^{+}\right]=\left[\mathrm{Cl}^{-}\right]+\left[\mathrm{OH}^{-}\right]
$$

All of the $\mathrm{Cl}^{-}$comes from the $\mathrm{HCl}$ and all of the $\mathrm{Na}^{+}$comes from the $\mathrm{NaOH}$. Using (3) and (4), we have

$$
\left[\mathrm{H}^{+}\right]^{2}-\left(\mathrm{x}_{\mathrm{a}}-\mathrm{x}_{\mathrm{b}}\right)\left[\mathrm{H}^{+}\right]-\mathrm{K}_{\mathrm{w}}=0
$$

From the definition of $\mathrm{pH}=-\log _{10}\left[\mathrm{H}^{+}\right]$, the $\mathrm{pH}$ titration curve for a strong acid-strong base is given by

$$
\mathrm{pH}=-\log _{10}\left(\frac{\mathrm{x}}{2}+\sqrt{\frac{\mathrm{x}^{2}}{4}+\mathrm{K}_{\mathrm{w}}}\right)
$$

where $\mathrm{x}=\left(\mathrm{x}_{\mathrm{a}}-\mathrm{x}_{\mathrm{b}}\right)$

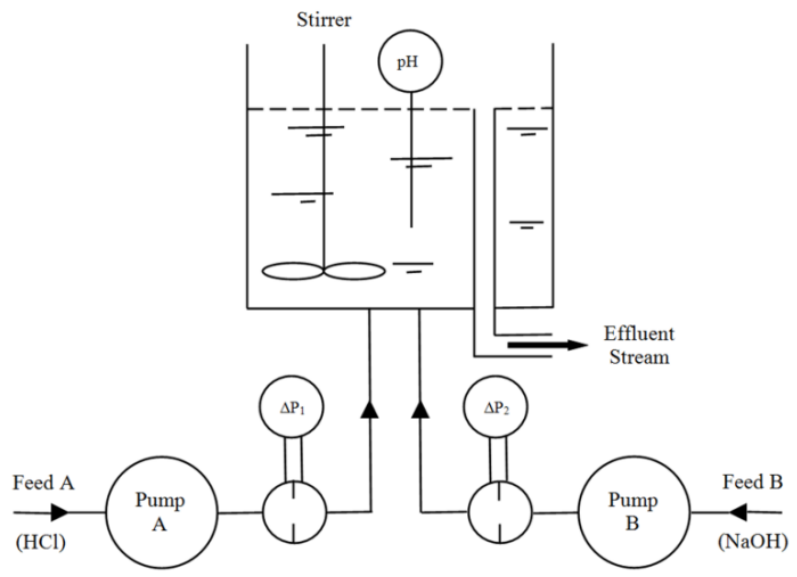

Fig. 1. pH Neutralization process

\section{DESIGN OF FUZZY CONTROLLER}

The fuzzy logic based controller for $\mathrm{pH}$ neutralization process is based on Mamdani FIS, most commonly used fuzzy methodology [17], [18]. It consists of an input stage known as fuzzifier, a processing stage known as fuzzy rule evaluator, and an output stage known as defuzzifier. The fuzzifier stage first determines the degree (a number between 0 and 1) to which each input belong to the appropriate fuzzy sets via membership functions. If the antecedent or premise (the IFpart of the rule) of a given rule has more than one part, the fuzzy operator is applied to obtain one number that represents the result of the antecedent for that rule. The processing stage first applies each rule's weight (a number between 0 and 1) to the number given by corresponding antecedent. The implication method is then applied on consequent or conclusion (the THEN-part of the rule), a fuzzy set represented by a membership function, of each rule. During implication process, each individual consequent is reshaped using the single number associated with the corresponding antecedent. Finally, using aggregation process, the truncated output functions are combined into a single fuzzy set. The defuzzifier stage takes the aggregate output fuzzy set as input and gives a single number as defuzzified output. The
Mamdani FIS used here assumes AND method for fuzzy operator, unity weight for every rule, minimum method for implication process, maximum method for aggregation process, and centroid method for defuzzification process.

The input variables used for the fuzzy logic based controllers are error (e) i.e. the difference between the desired $\left(\mathrm{pH}_{\mathrm{SP}}\right)$ and measured $(\mathrm{pH})$ values of control variable $\mathrm{pH}$, and change in error (ce) i.e. the difference between the error at the present and previous instants. The output variable used for the fuzzy logic based controller is the change in output (co) i.e. the change in flow rate of feed A. The membership functions for the input and output variables e, ce, and co are shown in Fig. 2, Fig. 3, and Fig. 4 respectively. The rule base for the input and output variables are shown in Table I.

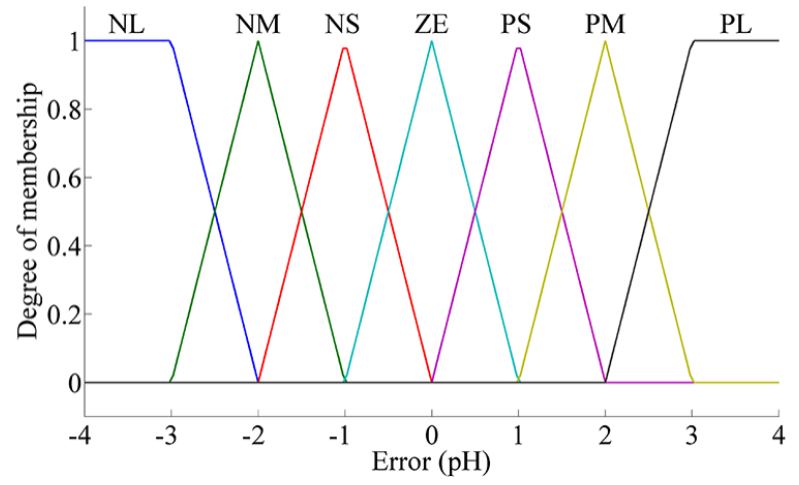

Fig. 2. Membership functions for error (e)

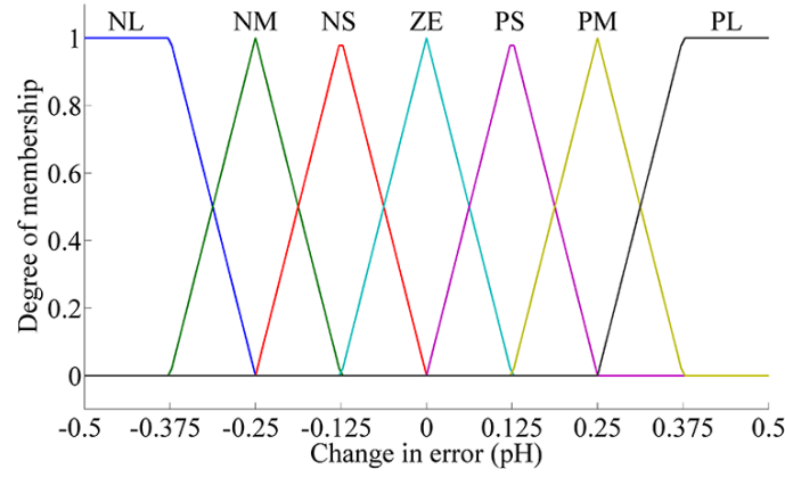

Fig. 3. Membership functions for change in error (ce)

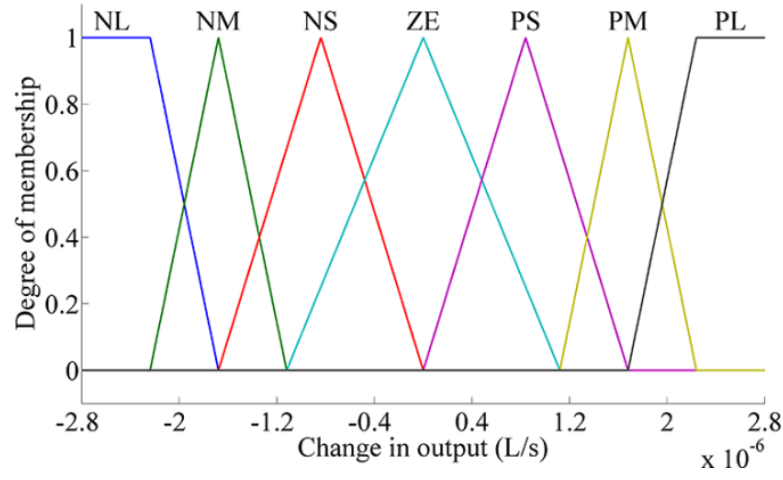

Fig. 4. Membership functions for change in output (co) 
Table I. Rule base for fuzzy logic control

\begin{tabular}{|c|c|c|c|c|c|c|c|c|}
\hline \multicolumn{2}{|c|}{} & \multicolumn{7}{|c|}{ ce } \\
\cline { 2 - 9 } \multicolumn{2}{|c|}{} & NL & NM & NS & ZE & PS & PM & PL \\
\hline \multirow{3}{*}{$\mathrm{e}$} & NL & NL & NL & NL & NL & NM & NS & ZE \\
\cline { 2 - 9 } & MN & NL & NL & NL & NM & NS & ZE & PS \\
\cline { 2 - 9 } & NS & NL & NL & NM & NS & ZE & PS & PM \\
\cline { 2 - 9 } & ZE & NL & NM & NS & ZE & PS & PM & PL \\
\cline { 2 - 9 } & PS & NM & NS & ZE & PS & PM & PL & PL \\
\cline { 2 - 8 } & PM & NS & ZE & PS & PM & PL & PL & PL \\
\cline { 2 - 8 } & PL & ZE & PS & PM & PL & PL & PL & PL \\
\hline
\end{tabular}

$\mathrm{NL}=$ Negative Large, $\mathrm{NM}=$ Negative Medium, $\mathrm{NS}=$ Negative Small, ZE = Zero, PS = Positive Small, $\mathrm{PM}=$ Positive Medium, $\mathrm{PL}=$ Positive Large.

\section{DESIGN OF LOOKUP TABLE BASED NEURAL CONTROLLER}

The design of neural network controller for $\mathrm{pH}$ neutralization process is carried out using a 2-D lookup table based on previously defined FIS [18], [19]. The $9 \times 9$ lookup table is generated by varying the input variables 'e', from -4 to 4 in step of 1 , and 'ce', from -0.5 to 0.5 in step of 0.125 , and computing the fuzzy logic output variable 'co' using centroid method, as shown in Table II. The neural network utilizes feedforward topology for its two layer architecture and backpropagation learning algorithm for its training. The number of neurons in input, hidden, and output layers are 2, 3, and 1 respectively. The activation function for both hidden as well as output neurons is "purelin". For the neural network, the training function is "traingdx", and the learning function is "learngdm". Finally, mean square error (MSE) is chosen as the performance function for the neural network. The 2-D lookup table provides a set of 81 input and target data. Using this data set, the neural network is being trained. The neural network training parameters are: 5000 as the maximum number of epochs, $10^{-12}$ as the performance goal, $10^{-10}$ as the minimum performance gradient, 0.5 as the learning rate, and 0.9 as the momentum constant. For the neural network, the training performance of $9.82 \times 10^{-13}$ is obtained in 236 epochs, and the regression value is 0.91 , as shown in Fig. 5 and Fig. 6 respectively.

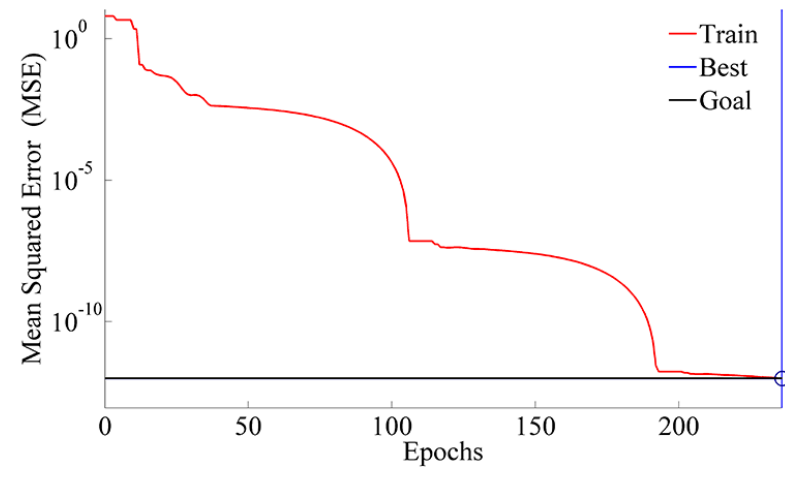

Fig. 5. Best training performance plot for the neural network

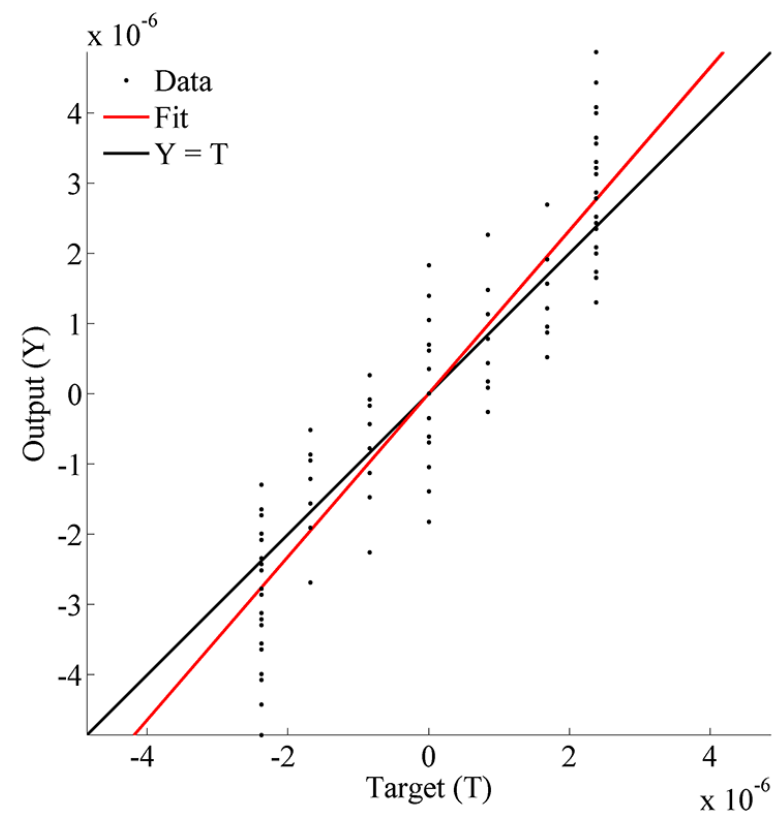

Fig. 6. Linear regression plot for the neural network

\section{RESULTS AND DISCUSSION}

The block diagram schematic of "intelligent" $\mathrm{pH}$ control of neutralization process is shown in Fig. 7. The "intelligent" controller block in the schematic diagram denotes either fuzzy logic based controller or lookup table based neural controller.

Table II. Two-dimensional lookup table

\begin{tabular}{|c|c|c|c|c|c|c|c|c|c|c|}
\hline & \multicolumn{9}{|c|}{ ce } \\
\hline & & -0.5 & -0.375 & -0.25 & -0.125 & 0 & 0.125 & 0.25 & 0.375 & 0.5 \\
\hline \multirow{9}{*}{$\mathbf{e}$} & -4 & $-2.38 \times 10^{-6}$ & $-2.38 \times 10^{-6}$ & $-2.38 \times 10^{-6}$ & $-2.38 \times 10^{-6}$ & $-2.38 \times 10^{-6}$ & $-1.68 \times 10^{-6}$ & $-8.4 \times 10^{-7}$ & $4.2 \times 10^{-23}$ & $4.2 \times 10^{-23}$ \\
\hline & -3 & $-2.38 \times 10^{-6}$ & $-2.38 \times 10^{-6}$ & $-2.38 \times 10^{-6}$ & $-2.38 \times 10^{-6}$ & $-2.38 \times 10^{-6}$ & $-1.68 \times 10^{-6}$ & $-8.4 \times 10^{-7}$ & $4.2 \times 10^{-23}$ & $4.2 \times 10^{-23}$ \\
\hline & -2 & $-2.38 \times 10^{-6}$ & $-2.38 \times 10^{-6}$ & $-2.38 \times 10^{-6}$ & $-2.38 \times 10^{-6}$ & $-1.68 \times 10^{-6}$ & $-8.4 \times 10^{-7}$ & $4.2 \times 10^{-23}$ & $8.4 \times 10^{-7}$ & $8.4 \times 10^{-7}$ \\
\hline & -1 & $-2.38 \times 10^{-6}$ & $-2.38 \times 10^{-6}$ & $-2.38 \times 10^{-6}$ & $-1.68 \times 10^{-6}$ & $-8.4 \times 10^{-7}$ & $4.2 \times 10^{-23}$ & $8.4 \times 10^{-7}$ & $1.68 \times 10^{-6}$ & $1.68 \times 10^{-6}$ \\
\hline & $\mathbf{0}$ & $-2.38 \times 10^{-6}$ & $-2.38 \times 10^{-6}$ & $-1.68 \times 10^{-6}$ & $-8.4 \times 10^{-7}$ & $4.2 \times 10^{-23}$ & $8.4 \times 10^{-7}$ & $1.68 \times 10^{-6}$ & $2.38 \times 10^{-6}$ & $2.38 \times 10^{-6}$ \\
\hline & 1 & $-1.68 \times 10^{-6}$ & $-1.68 \times 10^{-6}$ & $-8.4 \times 10^{-7}$ & $4.2 \times 10^{-23}$ & $8.4 \times 10^{-7}$ & $1.68 \times 10^{-6}$ & $2.38 \times 10^{-6}$ & $2.38 \times 10^{-6}$ & $2.38 \times 10^{-6}$ \\
\hline & 2 & $-8.4 \times 10^{-7}$ & $-8.4 \times 10^{-7}$ & $4.2 \times 10^{-23}$ & $8.4 \times 10^{-7}$ & $1.68 \times 10^{-6}$ & $2.38 \times 10^{-6}$ & $2.38 \times 10^{-6}$ & $2.38 \times 10^{-6}$ & $2.38 \times 10^{-6}$ \\
\hline & 3 & $4.2 \times 10^{-23}$ & $4.2 \times 10^{-23}$ & $8.4 \times 10^{-7}$ & $1.68 \times 10^{-6}$ & $2.38 \times 10^{-6}$ & $2.38 \times 10^{-6}$ & $2.38 \times 10^{-6}$ & $2.38 \times 10^{-6}$ & $2.38 \times 10^{-6}$ \\
\hline & 4 & $4.2 \times 10^{-23}$ & $4.2 \times 10^{-23}$ & $8.4 \times 10^{-7}$ & $1.68 \times 10^{-6}$ & $2.38 \times 10^{-6}$ & $2.38 \times 10^{-6}$ & $2.38 \times 10^{-6}$ & $2.38 \times 10^{-6}$ & $2.38 \times 10^{-6}$ \\
\hline
\end{tabular}




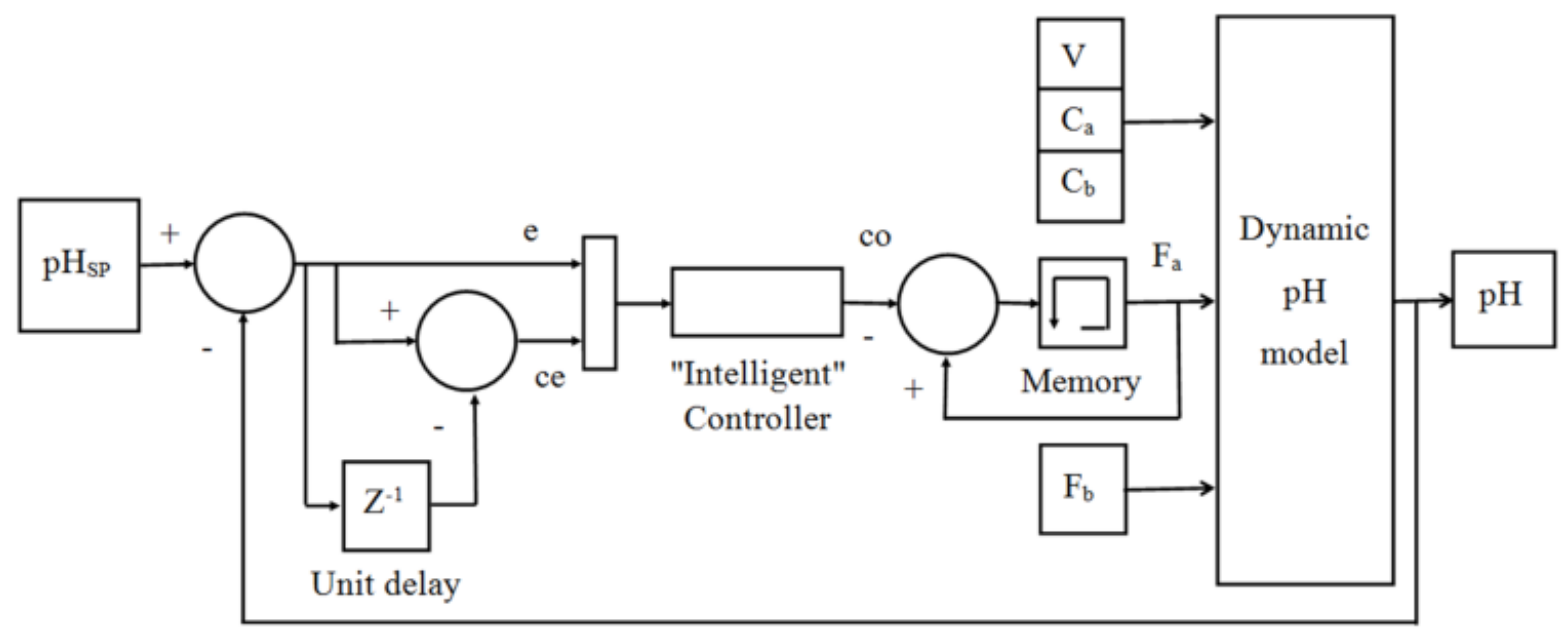

Fig. 7. "Intelligent" pH controller

The comparison of servo and regulatory response characteristic terms, such as rise and fall time, settling time (for $\pm 1 \%$ error band), maximum overshoot and undershoot, and decay ratio, for fuzzy logic based controller and lookup table based neural network controller are carried out using MATLAB simulation. To calculate overall performance parameters ISE and IAE, all the errors with magnitude greater than or equal to 0.01 are considered since further smaller errors will have negligible contribution.

\subsection{Servo operation}

For servo operation, as shown in Fig. 8, the $\mathrm{pH}$ set point $\left(\mathrm{pH}_{\mathrm{SP}}\right)$ is varied from 7 to 10 in unit positive step at sampling instants 500, 1000, and 2500 respectively; then from 10 to 4 in unit negative step at sampling instants 6000, 7500, 8000, 8500,9000 , and 10500 respectively; and finally from 4 to 7 in unit positive step at sampling instants 14000, 15500, and 16000 respectively. The flow rate of process stream $\left(\mathrm{F}_{\mathrm{b}}\right)$ is kept constant at its nominal value of $1.75 \mathrm{~mL} / \mathrm{s}$. The resulting variation of the controlled variable $(\mathrm{pH})$ and manipulated variable $\left(\mathrm{F}_{\mathrm{a}}\right)$ for fuzzy logic based control and lookup table

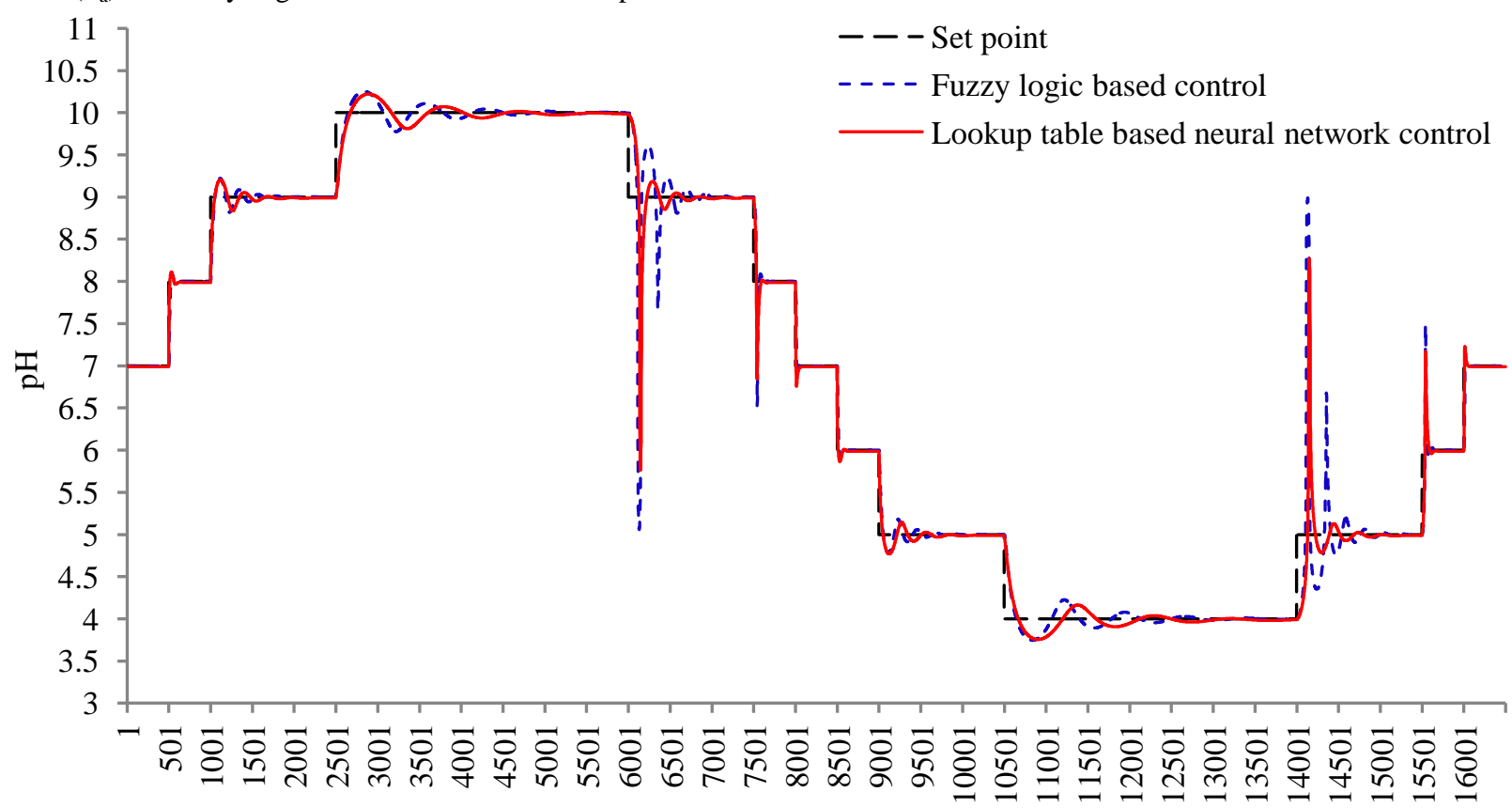

Sample number based neural network control techniques are shown in Fig. 8 and Fig. 9 respectively.

From Fig. 8 and Fig. 9, it is evident that the pH neutralization system response for lookup table based neural network controller has little more rise and fall time; but much reduced settling time, (maximum) overshoot and undershoot, and decay ratio. The reason behind this is the loosely fitted neural network with regression value of 0.91 only. In particular, when the $\mathrm{pH}$ set point changes from 10 to 9 and from 4 to 5 , the servo response characteristic terms is compared for both controllers, as shown in Table III and Table IV respectively.

For servo operation, the values of ISE and IAE for fuzzy logic based control technique are 1580.54 and 1548.10 respectively, whereas the corresponding values for lookup table based neural network control technique are 831.62 and 1277.14 respectively. Finally, both fuzzy logic based control technique as well as lookup table based neural network control technique is able to track the set point variation with negligible steady state error.

- - Set point

Fig. 8. pH variation due to servo operation 


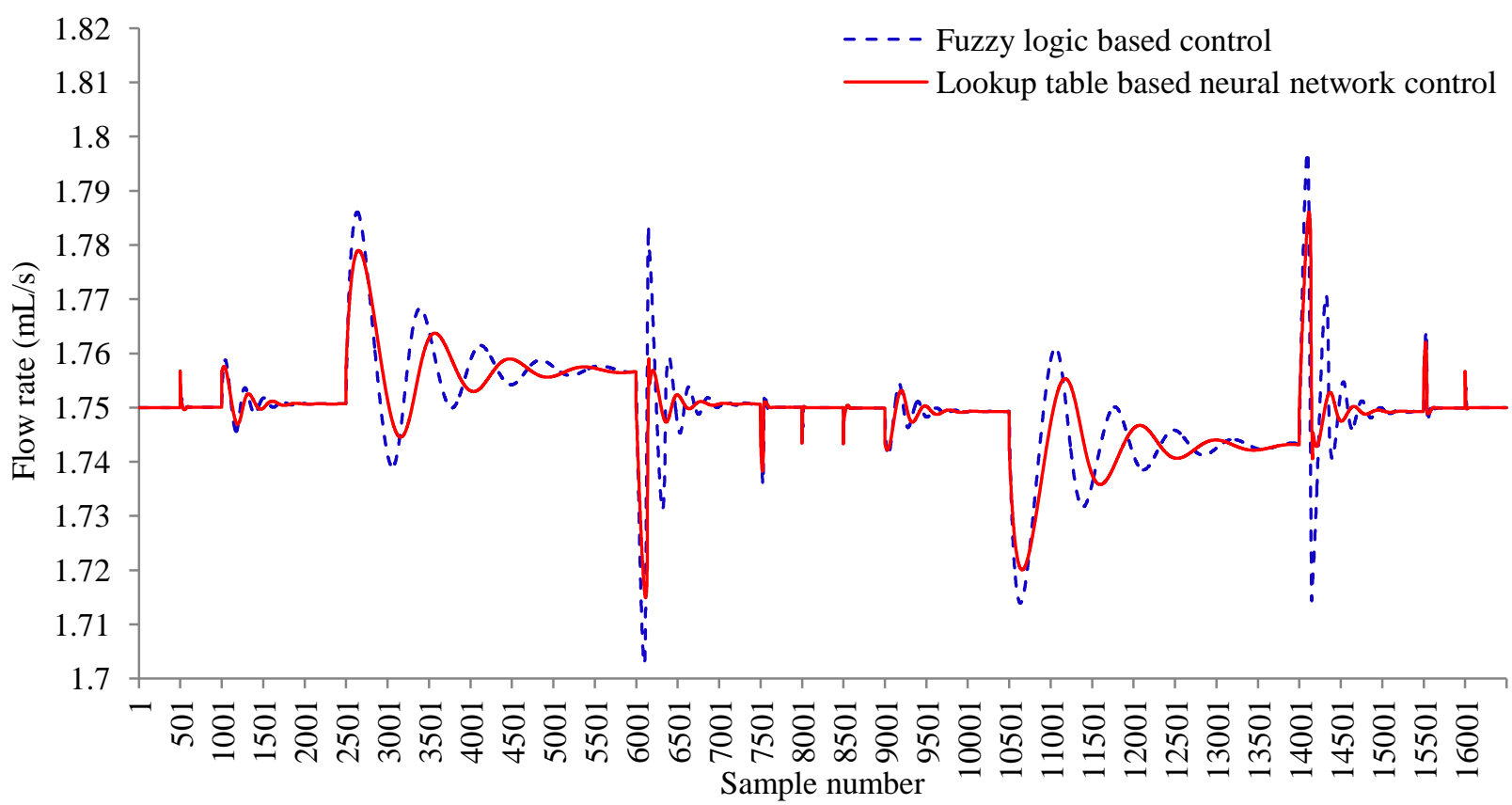

Fig. 9. Acid flow rate variation due to servo operation

For servo operation, the values of ISE and IAE for fuzzy logic based control technique are 1580.54 and 1548.10 respectively, whereas the corresponding values for lookup table based neural network control technique are 831.62 and 1277.14 respectively. Finally, both fuzzy logic based control technique as well as lookup table based neural network control technique is able to track the set point variation with negligible steady state error.

TABLE III. Characteristic Comparison for Set Point Change from 10 to 9

\begin{tabular}{|l|l|l|}
\hline & Fuzzy control & Neural control \\
\hline Fall time & 106 samples & 126 samples \\
\hline Settling time & 706 samples & 476 samples \\
\hline Maximum undershoot & 3.94 & 3.24 \\
\hline Decay ratio & 0.34 & 0.046 \\
\hline
\end{tabular}

TABLE IV. Characteristic Comparison for Set Point Change from 4 to 5

\begin{tabular}{|l|l|l|}
\hline & Fuzzy control & Neural control \\
\hline Rise time & 106 samples & 130 samples \\
\hline Settling time & 837 samples & 637 samples \\
\hline Maximum overshoot & 3.99 & 3.27 \\
\hline Decay ratio & 0.42 & 0.040 \\
\hline
\end{tabular}

\subsection{Regulatory operation}

For regulatory operation, as shown in Fig. 11, the flow rate of process stream $\left(\mathrm{F}_{\mathrm{b}}\right)$ is subjected to pulse disturbance of amplitude $\pm 1 \%$ of the nominal value and duration 200 samples at sampling instants 200 and 600 respectively; then of amplitude $\pm 3 \%$ of the nominal value and duration 500 samples at sampling instants 1000 and 2000 respectively; and finally of amplitude $\pm 5 \%$ of the nominal value and duration 1000 samples at sampling instants 3000 and 5000 respectively. The nominal flow rate of the process stream $\left(\mathrm{F}_{\mathrm{b}}\right)$ is taken as $1.75 \mathrm{~mL} / \mathrm{s}$. The $\mathrm{pH}$ set point is kept constant at 7 . The resulting variation of the controlled variable $(\mathrm{pH})$ and manipulated variable $\left(\mathrm{F}_{\mathrm{a}}\right)$ for fuzzy logic based control and lookup table based neural network control techniques are shown in Fig. 10 and Fig. 11 respectively.

From Fig. 10 and Fig. 11, it is clear that, as compared to the fuzzy logic based controller, the disturbance rejection is better for lookup table based neural network controller. For step disturbances of magnitude $\pm 5 \%$ of the nominal value at the sampling instants 3000 and 5000 respectively, the comparison of regulatory response characteristics for both controllers are shown in Table V and Table VI respectively.

TABLE V. Characteristic Comparison for $+5 \%$ Magnitude Step Disturbance

\begin{tabular}{|l|l|l|}
\hline & Fuzzy control & Neural control \\
\hline Rejection time & 337 samples & 278 samples \\
\hline Maximum undershoot & 2.69 & 2.79 \\
\hline Decay ratio & 0.86 & 0.57 \\
\hline
\end{tabular}

TABLE VI. Characteristic Comparison for $\mathbf{- 5 \%}$ Magnitude Step Disturbance

\begin{tabular}{|l|l|l|}
\hline & Fuzzy control & Neural control \\
\hline Rejection time & 348 samples & 283 samples \\
\hline Maximum overshoot & 2.69 & 2.78 \\
\hline Decay ratio & 0.87 & 0.58 \\
\hline
\end{tabular}


For regulatory operation, the values of ISE and IAE for fuzzy logic based control technique are 7975.78 and 3958.21 respectively, whereas the corresponding values for lookup table based neural network control technique are 7086.64 and 3433.00 respectively. Finally, both control techniques has negligible steady state error for regulatory operation.

\section{CONCLUSION}

Using a 2-D lookup table based on defuzzified FIS, a two layered neural network based controller is designed and is

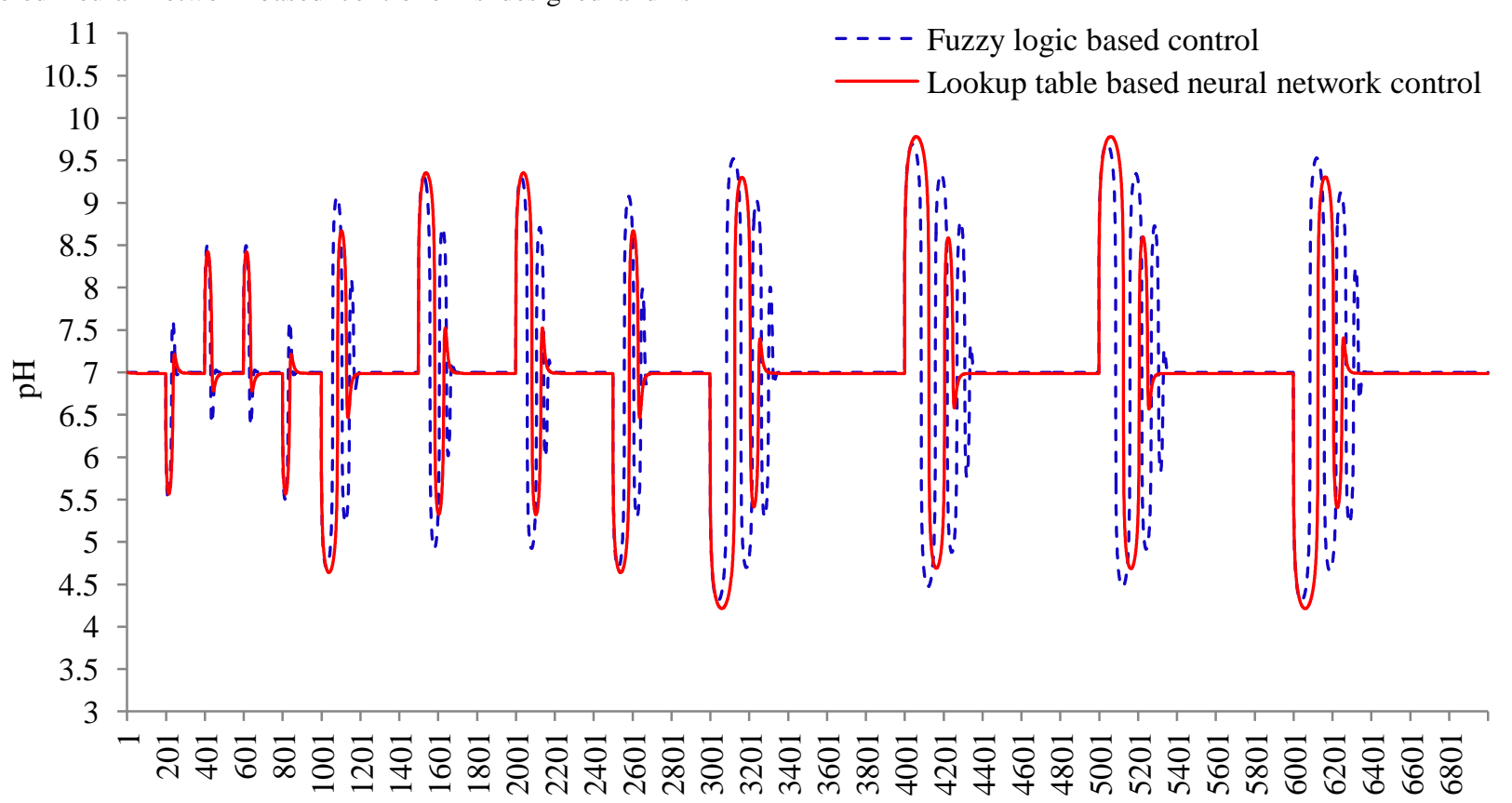

Sample number loosely trained to substitute the fuzzy logic based controller. Based on ISE and IAE values, it can be concluded that the proposed lookup table based neural network controller performs better than fuzzy logic based controller for both servo and regulatory operations. Also the steady state error present in lookup table based neural network controller is not appreciable and it can be neglected. To further improve the controller performance, optimization techniques may be applied.
- - Fuzzy logic based control

work control

Fig. 10. pH variation due to regulatory operation

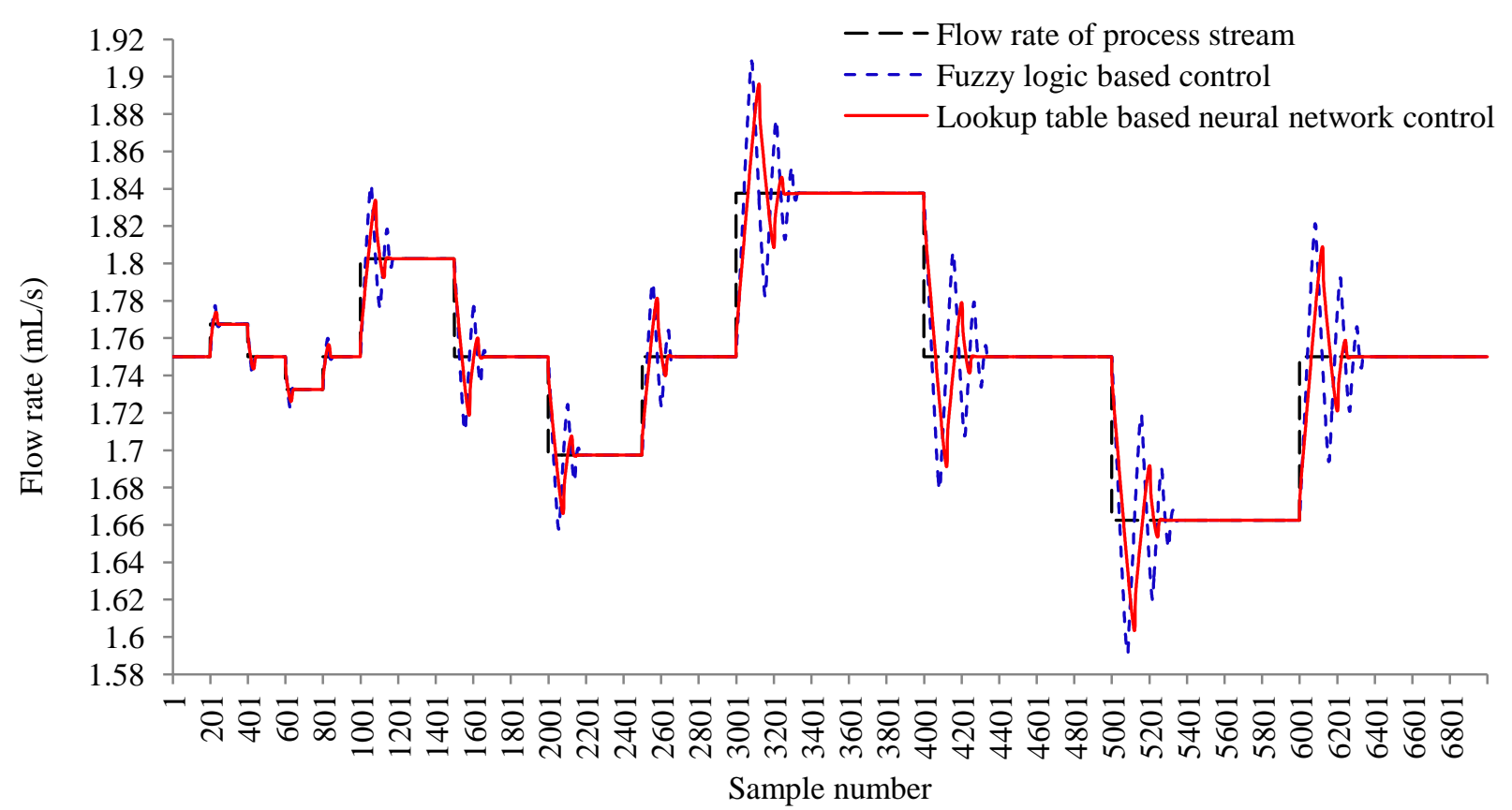

Fig. 11. Acid flow rate variation due to regulatory operation 


\section{REFERENCES}

[1] McAvoy, T.J., Hsu, E., and Lowenthals, S. Dynamics of $\mathrm{pH}$ in controlled stirred tank reactor. Ind. Eng. Chem. Process Des. Develop. 11 (Jan. 1972), 68-70.

[2] Gustafsson, T.K. and Waller, K.V. Dynamic modeling and reaction invariant control of $\mathrm{pH}$. Chemical Engineering Science 38 (Mar. 1983), 389-398.

[3] Wright, R.A. and Kravaris, C. Nonlinear control of $\mathrm{pH}$ processes using strong acid equivalent. Ind. Eng. Chem. Process Des. Develop. 30 (Jul. 1991), 1561-1572.

[4] Corriou, J.-P. 2008 Process Control: Theory and Applications. Springer (India) Pvt. Ltd.

[5] Shinskey, F.G. 1979 Process-Control Systems: Application / Design / Adjustment. McGraw-Hill Book Company.

[6] Liptak, B.G. 2006 Instruments Engineers' Handbook: Process Control and Optimization. CRC press.

[7] Seborg, D.E., Edgar, T.F., and Mellichamp, D.A. 2007 Process Dynamics and Control. Wiley India (P.) Ltd.

[8] Zadeh, L.A. Is there a need for fuzzy logic? Information Sciences 178 (Jul. 2008), 2751-2779.

[9] Zadeh, L.A. Fuzzy sets. Information and Control 8 (Jun. 1965), 338-353.

[10] Mamdani, E.H. Application of fuzzy logic to approximate reasoning using linguistic synthesis. IEEE Trans. Computers C-26 (Dec. 1977), 1182-1191.
[11] Takagi, T. and Sugeno, M. Fuzzy identification of systems and its applications to modeling and control. IEEE Trans. Systems, Man, and Cybernetics SMC-15, (Jan.-Feb. 1985), 116-132.

[12] Erenoglu, I., Eksin, I., Yesil, E., and Guzelkaya, M 2006. An intelligent hybrid fuzzy PID controller. In Proceedings of the 20th European Conference on Modeling and Simulation.

[13] Saji, K.S. and Kumar, M.S. 2010. Fuzzy sliding mode control for a $\mathrm{pH}$ process. In Proceedings of the IEEE International Conference on Communication Control and Computing Technologies.

[14] Daroogheh, N. 2009. High gain adaptive control of a neutralization process $\mathrm{pH}$. In Proceedings of the Chinese Control and Decision Conference.

[15] Bhat, N. and McAvoy, T.J. 1989. Use of neural nets for dynamic modeling and control of chemical process system. In Proceedings of the American Control Conference.

[16] Jang, J.-S.R. and Sun, C.-T. Neuro-fuzzy modeling and control. Proc. of the IEEE 83 (Mar. 1995), 378-406.

[17] Mamdani, E.H. and Assilian, S. An experiment in linguistic synthesis with a fuzzy logic controller. Int. J. Man-Machine Studies 7 (Jan. 1975), 1-13.

[18] Fuzzy Logic Toolbox User's Guide. The MathWorks Inc.

[19] Beale, M.H., Hagan, M.T., and Demuth, H.B. Neural Network Toolbox User's Guide. The MathWorks Inc. 